\title{
Diplomacia Corporativa. El caso de la cadena de hoteles Meliá
}

\author{
Corporate Diplomacy. Meliá Hotels case study
}

Amanda Arce Izquierdo ${ }^{1}$ y Palma Peña Jiménez ${ }^{2}$

URJC

amanda.arce.izquierdo@gmail.com; palma.peña@urjc.es

Recepción: 28/10/18 Revisión: 07/11/18 Aceptación: 08/11/18 Publicación: 28/12/18

\begin{abstract}
Resumen
Comunicar es imprescindible hoy para las instituciones, organizaciones o empresas. Lo importante es saber hacerlo y tener presentes los principales grupos de interés. Sobre este pilar se asienta la Diplomacia Corporativa, como herramienta que contribuye a gestionar las relaciones así como la comunicación, la imagen y la reputación de una compañía, institución u organización. La internacionalización y la globalización aconsejan que la comunicación corporativa deba añadir en sus relaciones institucionales todo lo que la diplomacia puede aportarle.
\end{abstract}

El presente artículo se centra en el concepto y aplicación de la "Diplomacia Corporativa» a las empresas e instituciones, así como en la figura del diplomático corporativo en las organizaciones y sus competencias. Además, planteamos un estudio de caso sobre la cadena Meliá Hotels International, pionera en crear un Gabinete Institucional y de Diplomacia Corporativa.

Palabras claves: diplomacia corporativa, comunicación corporativa, globalización, relaciones institucionales, rsc, reputación corporativa.

\section{Abstract}

Nowadays, Communication is essential for institutions, organizations or companies. The important thing is to know how to do it and keep in mind the main Stakeholders. Corporate

\footnotetext{
${ }^{1}$ Graduada en Relaciones Internacionales y Máster en Protocolo, Comunicación y Organización de eventos por la Universidad Rey Juan Carlos.

${ }^{2}$ Profesora de la Universidad Rey Juan Carlos. Coordinadora del Grado en Protocolo, Organización de eventos y Comunicación. Directora del Máster Universitario en Protocolo, Comunicación y Organización de eventos. Imparte docencia sobre Comunicación Corporativa. Sus líneas de investigación están centradas en la comunicación y en los nuevos procesos de aprendizaje.
} 
Diplomacy is based on this concept, as a tool that contributes to managing relationships as well as communication, corporate image and the reputation of a company, institution or organization. Internationalization and globalization advises that corporate communication should add, in its institutional relations, everything that diplomacy can provide.

This article focuses on the concept and application of "corporate diplomacy" to companies and institutions, and on the corporate diplomats and their competencies. We also propose a case study on the Meliá Hotels International chain, a pioneer in creating an Institutional and Corporate Diplomacy (CD) Cabinet.

Keywords: corporate diplomacy, corporate communication, globalization, institutional relations, CSR, Corporate reputation.

\section{Sumario}

1. Introducción

2. Diplomacia Corporativa

2.1 Introducción

2.2 Concepto de Diplomacia Corporativa

3. Estudio de Caso

4. Conclusiones

5. Bibliografía

\section{INTRODUCCIÓN}

La Diplomacia Corporativa, ámbito de la empresa muy extendido en el mundo anglosajón, pero no así en nuestro país, desarrolla disciplinas desde siempre muy relacionadas, pero que en el S.XXI evolucionan cada vez más deprisa como consecuencia de la globalización, la enorme competencia y los avances tecnológicos.

La existencia de perfiles profesionales que, formados en materias como las Relaciones Internacionales y la comunicación, buscan un futuro profesional que aúne ambos estudios en un mismo puesto de trabajo en la empresa, lleva a plantearse su encaje en el plano corporativo. En el ámbito privado, es habitual que se designen profesionales dedicados a la representación de los intereses de la organización como si fueran sus embajadores, hablamos de los diplomáticos corporativos. El interés suscitado por esta figura que actualmente existe en algunas empresas, bajo otro nombre, pero con las mismas características, es la motivación principal para conocer el alcance, la aplicación real y la utilidad de estos profesionales, que no son otra cosa que un Cuerpo Diplomático de embajadores corporativos que trabajan en la misma línea que el oficial.

La motivación, por tanto, que explica la investigación y desarrollo de esta temática es la necesidad de demostrar la eficacia y utilidad de la fusión de la diplomacia con la 
comunicación y las Relaciones Públicas en el ámbito empresarial y de las organizaciones en general.

El objetivo del presente artículo es dar visibilidad a una profesión que reúne diversas materias que son del interés de muchos y que pueden desarrollarse como perfil profesional. Además de definir y explicar en qué consiste la Diplomacia Corporativa, se desgranarán las habilidades con las que cuenta el diplomático, resaltando su importancia dentro de la empresa. Estas páginas pretenden también posicionar al protocolo como se merece en este ámbito, pues especialmente en el terreno de las Relaciones Internacionales es clave a la hora de establecer nexos con personas cuyas costumbres empresariales no coinciden con las locales.

Para la realización del trabajo, se va a utilizar una metodología de análisis documental en la que podemos observar dos tipos de consultas realizadas: por un lado, se van a consultar todos aquellos documentos publicados sobre esta materia, de manera más directa o más trasversal. Entre ellos, pueden encontrarse publicaciones de la década de los noventa e incluso anteriores, que sustentan las líneas dedicadas al ámbito de la diplomacia, las Relaciones Internacionales y su codificación. Al mismo tiempo, también se consultarán fuentes más recientes que se ocupan del tema objeto de estudio, centrados en la comunicación, tanto artículos académicos como artículos periodísticos y entrevistas con expertos en la materia.

Se establece un punto de partida a través de la presentación, explicación y profundización en el concepto de Diplomacia Corporativa para, más tarde, abordar el caso concreto de la cadena hotelera Meliá, examinando su estrategia y la puesta en marcha de un gabinete de Diplomacia Corporativa. Este análisis, nos permitirá tener una visión más amplia y práctica sobre lo que engloba la actividad y, a partir de ello, exponer las conclusiones tras el proceso de investigación.

\section{DIPLOMACIA CORPORATIVA}

\subsection{Introducción}

Las instituciones ya sean públicas o privadas, las corporaciones, organizaciones y empresas saben hoy que comunicar es imprescindible. Lo realmente necesario es saber planificar y ejecutar una estrategia que resulte eficaz. En torno a esta necesidad de la Comunicación Corporativa se entiende el concepto de "Diplomacia Corporativa» y del mismo modo cobra sentido la figura del diplomático en las empresas y organizaciones, como perfil profesional útil para gestionar la comunicación, la imagen, la reputación y la responsabilidad social (RS) de una compañía, institución u organización en un mundo globalizado.

Entenderíamos así sus funciones en plena sintonía o de manera paralela a las que desempeña la diplomacia en la representación de los Estados y en las Relaciones Internacionales. Trasladamos ese concepto al mundo de las organizaciones y empresas, así 
como la figura del diplomático corporativo como un actor que participa en la estrategia de creación de vínculos con los stakeholders.

De este modo la comunicación corporativa hoy se enriquece si en sus Relaciones Institucionales añade todo lo que la diplomacia pueda aportarle. En un mundo globalizado, la internacionalización de empresas e instituciones es una realidad. Acomodarse a los tiempos e incorporar a estas relaciones los contenidos y modos de estas disciplinas parece resultar coherente y de utilidad.

\subsection{Concepto de Diplomacia Corporativa}

El concepto de diplomacia, sin apellidos, es conocido por todos y lo relacionamos con el mundo de la representación institucional, designándole funciones de representación y negociación. De este modo, asumimos que la diplomacia surge y trabaja las relaciones entre grupos organizados, ya sean las relaciones entre los representantes institucionales designados por cada Estado para representarlo fuera de sus fronteras, o sean representantes de otras organizaciones para negociar cualquier asunto que les concierne.

La diplomacia, como ciencia, tiene su origen en la construcción de un sistema europeo de Estados. La consolidación de las embajadas permanentes a partir del s. XVI y XVII, así como las relaciones intergubernamentales y la configuración del llamado corps diplomatique, son el inicio de la diplomacia con base jurídica para representar a los diferentes Estados.

El Derecho de las Relaciones Diplomáticas comienza con el Congreso de Viena de 1815 , donde se adopta ya un reglamento sobre clasificación y precedencia de los enviados diplomáticos, completado después por el Protocolo del 21 de noviembre de 1818 de Aquisgrán. Ahora bien, la manifestación de mayor alcance y determinante en la codificación del Derecho Internacional en esta materia sucede en la segunda mitad del siglo XX bajo la Organización de Naciones Unidas (ONU). La Convención sobre Relaciones Diplomáticas de 1961 y que entra en vigor en 1964. A esto se añade la codificación de Relaciones Consulares que se adopta en 1963 y que está en vigor desde 1967 (PASTOR RIDRUEJO, 2012).

Toda esta reglamentación y el paso del tiempo han ido configurando las funciones diplomáticas que asumen la representación, la negociación, así como la protección de los intereses de los Estados y sus ciudadanos. En época más cercana se añade la función de cooperación en la que también se incluyen las organizaciones internacionales, las organizaciones no gubernamentales y las corporaciones transnacionales.

El concepto que aquí abordamos hace referencia directa a sus orígenes con los primeros contactos internacionales y la creación de las primeras empresas multinacionales. El origen de lo que hoy se conoce como Diplomacia Corporativa (KSD, 2013) se encuentra en las primeras empresas transnacionales dedicadas al comercio, tales como la Compañía Británica de las Indias Orientales, la compañía Neerlandesa de las Indias Orientales en 1602, 
la banca Rothschild en el s. XVIII, y la Muscovy Trading Company que monopolizó el comercio entre Inglaterra y Moscú en los siglos XIV y XVI.

El Instituto Internacional de Diplomacia Corporativa señala que "la globalización ha incrementado la complejidad de los entornos de negocio, lo que obliga a las organizaciones del s. XXI a adquirir nuevas capacidades y habilidades para mejorar la competitividad internacional" a lo que podríamos añadir que también son convenientes estas habilidades en las relaciones entre instituciones y empresas dentro de su ámbito territorial. El Instituto considera, además, la Diplomacia Corporativa como el desarrollo instrumental de la estrategia de la influencia. Sigue en este sentido lo que apuntara WATKINS ${ }^{3}$, quien la define como el papel que juegan los altos ejecutivos en la promoción del interés social mediante la negociación y la creación de alianzas con actores externos clave, incluyendo gobiernos, analistas, medios de comunicación y organizaciones no gubernamentales (ONG).

HENISZ (2014) entiende la Diplomacia Corporativa como la capacidad de alto nivel para construir y mantener relaciones con los grupos de interés externos y cumplir así con las necesidades y objetivos más importantes entre las partes interesadas. TRUJILLO (2011), quien fuera directora del Gabinete Institucional y Diplomacia Corporativa de Meliá, destaca la necesidad de las empresas de relacionarse con sus grupos de interés como palanca para su posición de liderazgo. MANFREDI (2018), por su parte, señala que la necesidad de diplomacia corporativa surge, en primer lugar, de la globalización que ha llevado a la internacionalización de la economía y de la empresa. Según este autor "la diplomacia corporativa es una función propia de la innovación directiva en el siglo XXI", ya que las instituciones y empresas se mueven en un ámbito en muchos casos ya internacional, con actividad exterior, además de la actividad digital que nos posiciona de manera global.

A todo lo anterior podríamos añadir los beneficios que la Diplomacia Corporativa ofrece en la gestión de conflictos y que "puede ayudar a las empresas a manejar de manera responsable y estratégica un entorno empresarial fragmentado, volátil y, en cierta medida, hostil" (STEGER 2003: 15-19).

En definitiva, se trata de una herramienta útil que favorece las relaciones de las instituciones, corporaciones, organizaciones o empresas sobre todo en un mundo globalizado, donde las relaciones ya no son solo de cercanía y donde las oportunidades de crecimiento se encuentran en muchas ocasiones en lugares emergentes. Por este motivo las compañías necesitan un profesional que pueda llevar a cabo similares labores a las del diplomático en representación de su Estado, un profesional que sepa planificar, organizar y gestionar las relaciones con los stakeholders que, como apunta SERRANO (2008) "son los depositarios de la imagen de la empresa, a la vez que sus fiscales", que sepa gestionar a su vez las relaciones con las administraciones locales, nacionales o internacionales, así como con cuantas entidades puedan interesar para finalmente trabajar en la reputación de la marca o institución, en su prestigio y, cómo no, en sus resultados económicos.

\footnotetext{
${ }^{3}$ Dr. Watkins, profesor de la Kennedy School of Government de la Universidad de Harvard.
} 
La Diplomacia Corporativa resulta así no solo útil, sino también conveniente porque gestionar iniciativas que ayudan a las empresas, a las organizaciones $\mathrm{o}$ a las instituciones a posicionarse y diferenciarse de manera positiva y de este modo poder competir también internacionalmente. La capacidad de relación es hoy necesaria para avanzar y conseguir el reconocimiento reputacional. Generar lazos y establecer redes de cooperación con otras instituciones, empresas y organizaciones afines contribuye también a nuestro propio éxito.

Además, este concepto de gestión de las relaciones ayuda a trasmitir y comunicar los logros relacionados también con su Responsabilidad Social. Su posicionamiento ante los temas sociales, temas sensibles, derechos de sus trabajadores y código ético. TRUJILLO (2011: 37) señala la importancia de esta dimensión ética de la Diplomacia Corporativa, entendiendo "la responsabilidad social como un ingrediente más en la relación y diálogo con los grupos de interés".

El diplomático corporativo "cubre la mayoría de las parcelas que deben tomarse en consideración para asegurar que los objetivos empresariales puedan llegar a buen puerto. De entrada todos aquellos que contribuyen a la reputación, a la percepción y a la credibilidad de las empresas, propiciando un conocimiento acorde con la realidad y un diálogo fluido con todos los agentes sociales implicados" (MANFREDI, 2012). Puede contribuir, junto con el DIRCOM, en el plan integral de comunicación, en su gestión y coordinación, con el objetivo de posicionar a la organización o institución donde merece. Además "no podemos olvidar que los actos o eventos son acciones de comunicación y deben trasladar, acordes a la identidad y personalidad de la institución, un mensaje coherente" (PEÑA, 2018: 420). En esta tarea, el diplomático corporativo añade sus conocimientos específicos, cumpliendo con un papel que puede resultar determinante para el buen ejercicio de las relaciones institucionales y que serán determinantes para posicionar y trabajar la comunicación corporativa de manera integral.

\section{ESTUDIO DE CASO. MELIÁ HOTELS INTERNATIONAL}

En España son ya varias las empresas que cuentan con profesionales dedicados a funciones relacionadas con la Diplomacia Corporativa, tales como Iberdrola, Santander, Telefónica o Repsol. Sin embargo, la primera en crear un Gabinete Institucional y de Diplomacia Corporativa propiamente dicho fue la compañía hotelera Meliá.

Nuestro análisis se centra en la cadena Meliá, no solo porque fue pionera en crear un Gabinete Institucional y de Diplomacia Corporativa con un modelo propio, centrado en la comunicación y la gestión de los stakeholders, sino también porque nos muestra un modelo para integrar la figura del diplomático corporativo que puede ayudar a entender la figura y sus funciones.

Meliá es una compañía hotelera de carácter internacional que en la actualidad dispone de más de 370 hoteles distribuidos en 43 países y en 4 continentes. Fundada en 1956 en Palma de Mallorca (España), fue la primera empresa hotelera en salir a bolsa en 1996. 
La compañía tiene una estrategia de Sostenibilidad y RSC muy clara, estudiada y afianzada. Entre sus compromisos más destacados se encuentran la protección del medio ambiente y de la infancia. Así, está incluida en el índice Carbon Disclosure Project (CDP), en el índice responsable de la bolsa española FTSE4Good, es firmante del Global Compact de Naciones Unidas y mantiene una alianza estratégica con UNICEF y con diversas organizaciones y plataformas en defensa de la integración y empleabilidad de los jóvenes. Esta estrategia de RSC está dirigida a satisfacer a todos sus grupos de interés. Es decir, el objetivo no es únicamente rentabilizar la inversión, generar valor para los accionistas, propietarios e inversores, y ofrecer la mejor experiencia para los clientes, sino también implicarse en la prosperidad y el desarrollo sostenible de las comunidades donde opera, además de velar por el entorno donde desarrolla sus actividades. Todo ello pasa por tratar de construir relaciones duraderas y de confianza con los proveedores, y ofrecer las mejores oportunidades de desarrollo profesional a sus colaboradores, reconociendo su talento.

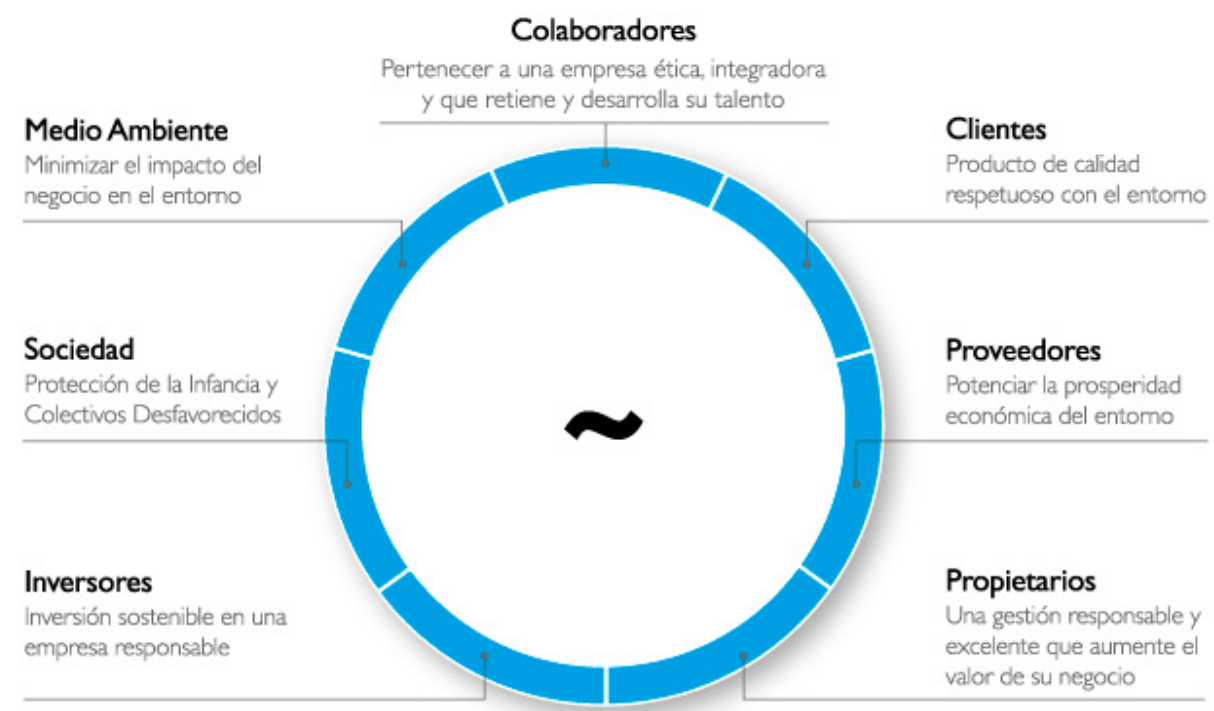

Imagen 1: Integración en la cadena de valor.

Fuente: Meliá Hotels International (Consultado 20/05/2017)

El principal valor de la compañía en sus relaciones es el compromiso, lo cual se refleja en su Código Ético, cuya aplicación significa, según su fundador y presidente ESCARRER (2010): “Asumir [...] la responsabilidad que implica que otros se miren en nosotros y reconozcan nuestro liderazgo. Pero también [...] proteger lo que tantos años llevamos construyendo entre todos los que hacemos Meliá Hotels International: nuestra reputación". En definitiva, según dicha afirmación, la reputación de una compañía, depende en gran medida de unas relaciones sostenibles con sus grupos de interés.

Las características que definen la labor de diálogo de la Compañía con sus stakeholders se resumen en el acrónimo CERCA. Este acrónimo integra las palabras Conoce, Escucha, 
Responde y Cambia. En otras palabras, primero se identifican los grupos de interés y su localización, después se habilitan los espacios de encuentro con los mismos para la escucha activa y posterior elaboración de una propuesta para cada grupo. Finalmente, se llevan las propuestas a la práctica adaptando las políticas a las expectativas de cada uno de ellos.

Así, la hotelera entrelaza la estrategia de RSC y la Diplomacia Corporativa. Mientras se aplica una visión de comportamiento sostenible a nivel interno, a nivel externo se busca estrechar lazos y establecer diálogo con los grupos de interés. Se trata de conjugar la responsabilidad, el compromiso y la sostenibilidad que caracterizan la RSC con las labores de representación y relación, que favorecen la reputación de la marca, ámbito estrechamente relacionado con los anteriores.

Esta concepción global de Meliá responde a la teoría que Sebastián Escarrer, Consejero Externo Dominical de Meliá Hotels International, explicaba afirmando que "si no suceden cambios dentro, no hay nada que contar fuera y sobre lo que construir la posición pública" (CARAZO, 2011).

Meliá es un buen ejemplo de la eficacia que supone cuidar las relaciones y el entorno. El modelo de Diplomacia Corporativa que ha puesto en marcha la empresa no sólo es una forma eficaz de mejorar sus relaciones institucionales -especialmente con las Administraciones Públicas-, sino también su reputación corporativa, ya que la meta es que la sociedad elija Meliá no sólo por la calidad de las experiencias que ofrece, sino por mostrar una actitud respetuosa y preocupada por todo aquello que rodea a la Compañía. Es decir, trabajar teniendo en cuenta nuestras creencias, nuestra posición y haciéndolo con una narrativa corporativa coherente para pueda convertirse en reputación.

A esta forma de entender la misión y los valores de la empresa, hay que añadir el deseo de sensibilización de cara al ciudadano. En palabras de ESCARRER (2010): "Nos gusta pensar que podemos convertir nuestros hoteles en escuelas de ciudadanía. Con la ayuda de los empleados, podemos hacer que el cliente se sienta partícipe de nuestro compromiso con la sostenibilidad".

Meliá recoge todo ese compromiso de sostenibilidad, explicado con anterioridad en un decálogo que concentra las intenciones de la empresa con respecto a los stakeholders y que se integra en la cadena de valor de la compañía, principalmente a través de la construcción y participación en iniciativas sostenibles, la gestión eficiente de los recursos, la eficiencia energética, la promoción del empleo en las comunidades locales, la estancia del cliente y la oferta gastronómica saludable.

Por tanto, el modelo de Diplomacia Corporativa de Meliá se basa, tal y como señala TRUJILLO, citado en BAJO \& VILLAGRA (2011, p. 46-48) en tres ejes: la gestión de la información, la gestión de las relaciones, y la representación y participación institucional.

1. Gestión de la información: por un lado la relación con los grupos de interés. Se analizan las tendencias -información externa-, aunque el diplomático corporativo 
también tiene una responsabilidad con respecto a la información interna, ya que también se encarga y contribuye en la construcción de los mensajes, de sustentarlos sobre bases sólidas y de enriquecerlos para darles valor ante los públicos.

2. La gestión de las relaciones: la Diplomacia Corporativa de Meliá ejerce una función de representación doble, por un lado la de intermediario, tratando de conseguir que las demandas de los grupos de interés sean transmitidas y gestionadas; y también la de defensa estratégica de los intereses de la compañía ante esos grupos. Según ESCARRER (2010), "El cómo escuchamos de una forma activa a los stakeholders, cómo nos adaptamos y cómo tendemos un puente entre el mundo exterior y el mundo interior para hacer que la empresa se gestione pensando continuamente en la creación de valor, es lo que hace que la rentabilidad a medio y a largo plazo esté garantizada".

3. En cuanto a la representación y participación institucional, el diplomático corporativo se encarga tanto de proyectar la personalidad de la empresa como de hacer que la imagen pública de la compañía y su identidad interna coincidan. Es decir, se trata de hacer de puente entre la cara interna de la empresa y sus públicos.

En definitiva, el Gabinete de Diplomacia Corporativa de Meliá aglutina todas las funciones que se derivan de tres grandes ejes (BAJO \& VILLAGRA, 2011: p. 46-48): las relaciones institucionales, la comunicación corporativa y la reputación corporativa. De ello se extrae que, dentro de estos tres ámbitos de actuación, se encuentran las disciplinas de las que sin duda depende un Gabinete de esta índole: la diplomacia para propiciar las relaciones institucionales; en el ámbito de la comunicación, el diálogo con los stakeholders y la celebración de eventos, cumbres y foros como punto de encuentro con esos grupos; la RSC como facilitador de una buena reputación corporativa; y el protocolo como elemento integrador para dar coherencia, orden y adecuación a las relaciones empresariales o institucionales, sobre todo cuando se trata con interlocutores de culturas diversas, donde es vital no debilitar los esfuerzos en la negociación por desconocimiento de las normas protocolarias.

\section{CONCLUSIÓN}

Tras el estudio del concepto de Diplomacia Corporativa y el análisis centrado en la cadena Meliá podemos concluir señalando que:

1. La Diplomacia Corporativa tiene mucho que ofrecer, ya que plantea un tipo de gestión que aúna la comunicación como herramienta, el ejemplo de la diplomacia tradicional como referente, y el protocolo como guía, sin olvidar los valores en los que se basan sus políticas de responsabilidad social corporativa.

2. En España no está todavía consolidada en la estructura y organigrama de las empresas como sí sucede en el ámbito anglosajón. Nos encontramos en un momento incipiente, ya que la Diplomacia Corporativa todavía es desconocida, pero posiblemente con el paso del tiempo encontraremos la figura del diplomático 
corporativo en las organizaciones, sobre todo si tienen una clara vocación internacional.

3. Introducir la Diplomacia Corporativa en las instituciones, organizaciones y empresas contribuye a estrechar las relaciones con los grupos de interés, bien sean gobiernos, instituciones y ciudadanos en todos los niveles territoriales del Estado y fuera de él. Para que esas relaciones prosperen, se han de tener interlocutores con habilidades que van más allá de las competencias comerciales tradicionales.

4. El perfil del diplomático corporativo es un híbrido entre un diplomático y un profesional de la comunicación, que aúna conocimientos y competencias en materia de comunicación, diplomacia y protocolo. Sus conocimientos de protocolo e interculturales facilitarán las relaciones que tengamos que establecer con otras instituciones u organizaciones. Sería conveniente que el profesional que la ejerciera ocupara un lugar adecuado dentro del organigrama, ya que debe formar parte de la estrategia integral de la institución o empresa.

5. La cadena hotelera Meliá, además de ser pionera en la creación de un Gabinete de Diplomacia Corporativa, ha demostrado cómo una gran empresa es capaz de crear un departamento que gestione conjuntamente materias como las Relaciones Institucionales y la RSC. Meliá y su gestión de la Diplomacia Corporativa son la prueba de que es posible combinar en un único Gabinete perfiles profesionales que se han formado tanto en campos como las Ciencias Políticas y de la Administración o las Relaciones internacionales, como en Comunicación, Responsabilidad Social Corporativa, o Protocolo Institucional y empresarial.

\section{BIBLIOGRAFÍA}

BAJO, A., \& VILLAGRA. Los grandes retos de la empresa en el S. XXI. Madrid, España: Publicaciones Universidad Pontificia de Comillas. Capítulo 3: La diplomacia corporativa como disciplina de gestión empresarial - Caso Meliá.

CARAZO, J. (28 de Marzo de 2011). Cinco Días. Meliá impone en RSC la diplomacia corporativa. Cinco Días. Recuperado de https://cincodias.elpais.com/cincodias/2011/03/28/empresas/1301319595_850215.html

ESCARRER, S. (04 de Noviembre de 2010). Entrevista con IESE Insight Business Knowledge. Recuperado de http://www.ieseinsight.com/fichaMaterial.aspx?pk=6649\&idi=1\&origen=1\&idioma=1

Instituto Internacional de Diplomacia Corporativa. (s.f.). Recuperado de http://iiDiplomacia Corporativa.es/

HENISZ, W. (5 mayo de 2014). "Corporate Diplomacy": Why Firms need to build ties with external stakeholders (S.J. Kobrin. Entrevistador). IN "Building reputations and relationship with external stakeholders. 
KSD International. (28 de Enero de 2013). Diplomacia corporativa: delimitando el concepto.

Recuperado de https://ksdinternational.wordpress.com/2013/01/28/diplomaciacorporativa-delimitando-el-concepto/

MANFREDI, J. L. (Cinco Días (23/07/2012). Diplomacia corporativa y alta dirección. Recuperado de http://blogs.cincodias.com/escuelasdenegocio/2012/07/diplomaciacorporativa-y-alta-direcci\%C3\%B3n.html

MANFREDI (2018) https://www.nobbot.com/general/la-diplomacia-corporativa-siglo-xxi/ (recuperado el 08/09/2018)

PASTOR RIDRUEJO, J. A. (2012) Curso de Derecho Internacional Público y Organizaciones Internacionales. Decimosexta edición. Madrid: Tecnos.

PEÑA, P. (2018) “Comunicación y Protocolo" En: Cuadernos de la Escuela Diplomática, núm 62. Ministerio de Asuntos Exteriores, Unión Europea y Cooperación. pp. 419-429.

SERRANO, F.C. (2008) "Aspectos éticos y deontológicos del ejercicio profesional de la Comunicación Corporativa". En: Revista de Comunicación y Nuevas Tecnologías, 1.

STEGER, U. (2003). Corporate Diplomacy. En U. Steger, Corporate Diplomacy (pp. 15-19). Sussex. Wiley

TRUJILLO, E. (2011). La diplomacia corporativa, o el arte de las decisiones compartidas. Harvard Deusto Business Review, pp. 36-37.

WATKINS, M. D. (Mayo 2017). The rise of Corporate Diplomacy (Finally!). Harvard Business Review. Recuperado de https://hbr.org/2007/05/the-rise-of-corporate-diplomac

\section{Otras fuentes:}

Meliá Hotels International. (s.f.). Acerca de. Recuperado de http://www.meliahotelsinternational.com/es/acerca-de/conoce-mhi

Meliá Hotels International. (s.f.). Premios y reconocimientos. Recuperado de http://meliahotelsinternational.com/es/acerca-de/premios-y-reconocimientos

Meliá Hotels International. (s.f.). Responsabilidad Corporativa. Recuperado de http://www.meliahotelsinternational.com/es/responsabilidad-corporativa/rsc

Meliá Hotels Internacional. (s.f.). Meliá Hotels International. Recuperado de http://www.meliahotelsinternational.com/es/responsabilidad-corporativa/melia-cerca

Meliá Hotels International. (s.f.). Decálogo de sostenibilidad. Recuperado de http://www.meliahotelsinternational.com/es/responsabilidadcorporativa/posicionamiento/decalogo-sostenibilidad 
Meliá Hotels Internacional. (2016). Código Ético. Recuperado de http://www.meliahotelsinternational.com/es/accionistas-e-inversores/gobiernocorporativo/codigo-etico

Meliá Hotels International. (s.f.). Integración de la cadena de valor. Recuperado de http://www.meliahotelsinternational.com/es/responsabilidad-corporativa/integracioncadena-valor 